\title{
Optimal Design and Power Management in Shipboard System
}

\author{
Teja Sree Mummadi ${ }^{1}$ and Dr.R.Vijay ${ }^{2}$ \\ ${ }^{1}$ PG Scholar, CVR College of Engineering/ EEE Department, Hyderabad, India \\ Email: tejamummadi54@gmail.com \\ ${ }^{2}$ Assoc. Professor, CVR College of Engineering/ EEE Department, Hyderabad, India \\ Email: vijai.mtp@gmail.com
}

\begin{abstract}
This paper deals with controlling DC power in shipboard power. Shipboard Power System (SPS) experiences disturbance due to variations in load. A DC bus distribution system developed for the U.S. Coast Guard's 270-ft Medium Endurance Cutter is simulated using MATLAB in this paper. Whenever a fault occurs in load, the system power varies. In this paper, the DC power system is controlled automatically by detecting disturbances. The proposed method includes selfgoverning fault detection and controlling DC power. The shipboard power system consists of a challenge related to restoration. The reliability and flexibility of the system are improved with effective integrated Energy Storage Devices (ESD) and Solar power. A maiden attempt is made in the paper with a solar panel for the cost-effective operation of the SPS. Also, the SPS with and without the solar panel is tested for optimal operation. Furthermore, this shipboard management system may be implemented in the Indian shipboard system for optimal power management.
\end{abstract}

Index Terms: Optimal power management, DC bus distribution system, shipboard power system, energy storage system, solar power, fault detection, energy storage device.

\section{INTRODUCTION}

The ships which are used for both military and commercial purposes which works based on electricity are enabled by Integrated Power Systems (IPS). This IPS is now used to meet increasing demand. In critical conditions, i.e., when there is a change in load or IPS component failure, they provide real-time management for dynamic configuration to support system.

Recently, there has been much advancement in controlling and managing DC microgrid. These advancements have been implemented in applications such as traction, smart buildings, shipboard power systems and many more. The drastic development in semiconductor devices and power electronic devices over the last two decades made a way for advanced electrical networks, which are useful in automotive, space, and marine applications. These systems deliver with high efficiency and reliability [1], [2]. Because of the advancement in power electronics, DC distribution systems have gained more attraction than AC.

Though there are many advantages to the DC-based integrated power system, it is difficult to maintain optimal performance without interruption with a dynamic load. The protection schemes can detect faults and isolate them, but they do not consider the optimization constraints or balance the power after fault isolation. To meet the increasing DC shipboard power demand, all the electric ships are implementing the integrated power system [3]. They have to manage the power for the dynamic profile to support the system critical operations when there is a change in dynamic load or IPS failure.

In the IPS architecture, all the loads are supplied by a common electrical power bus, which enables the handling of the loads and generation sources more optimal and efficiently. It is able to deliver direct power to vital loads on demand [4].

A new method is introduced which controls and optimally reform a DC power system, while automatically detecting system disturbances. A dynamic approach is proposed using time scale separation. The aim is to provide coordination between system protections to ensure that the system remains stable at all stages of operation even when there is a disturbance.

To implement the approach called DC-based shipboard power system is employed. The reliability of electrical power plays a major role in this modern world. As the demand for electrical power is increased there should be an alternative for restoration and recovery after an outage or fault on the system [5]. In this case, if the power system is provided with storage devices, it can provide back-up power or power during the transition [6]. In this paper, DC Shipboard Power System (SPS) is integrated with the Energy Storage System, which acts as a feedback path.

An Energy Storage Device Subsystem is very necessary for the shipboard power system and for terrestrial electrical systems. This element helps in storing a large amount of energy, which can be used as a back-up. During any fault conditions, the electrical system can be fed by ESDs. The outage of electrical equipment and other parts or operational issue may occur if ESDs fail to provide energy during faults [7-8].

Recent developments of SPSs include integrated circuits and which are trending nowadays. Due to the advantages of DC over AC, the DC shipboard came into existence. Generally, there are two types of distribution system that includes radial type and ring type distribution system. Convectional SPSs are of radial type distribution systems.

The radial type system has a generating station at the center of the loads. The power flow is in only one direction. In radial type, if any fault occurs then it would result in loss of supply to many units until the fault is located and cleared. 
When there is a change in a generation it seriously affects the load side which results in voltage fluctuations, due to this reliability and stability decrease. But recently to overcome radial distribution problems zonal distribution system is implemented. The researchers proposed a new technology that includes both radial distribution architecture and zonal approach. The zonal approach [9] employs a Starboard Bus (SB) and a Port Bus (PB), and thus dividing the ship into a few electric zones.

In this paper, the DC SPS is integrated with the Energy Storage System (ESS) where the battery is used as Energy Storage Device. By integrating the ESS with the DC SPS the system efficiency is improved. The ESS acts as a backup of the system.

ESS technologies are technologically viable nowadays. A few of them are Flywheels, the Superconducting Magnetic Energy Storage (SMES), Battery Energy Storage System (BESS), the Compressed Air Energy Storage (CAES), Super Capacitors and Pumped Hydro Storage (PHS). Either AC or DC system, for charging and discharging purposes the ESS requires power converters. Mostly used ESS is an Uninterruptible Power Supply (UPS). In this paper, the battery is used for Energy Storage Device.

This paper deals with the modeling of DC SPS with solar resources for power generation. Solar panel technology requires a power converter to boost the output power. In this paper boost converter is used as a converter for a solar panel. The buck-boost converter is integrated with ESS as a power converter.

The remaining of this paper is outlined as follows: Section II introduces about SPS configuration. Section III is about SPS power control. The modeling and simulation circuit and results are shown in Section IV. Conclusions are presented in Section V.

\section{SHIPboARD POWER System}

\section{A.Shipboard Configuration}

An Electrical power distribution system for the ship must be able to provide power generation and distribution, control and some basic power electronics operations. Space and weight parameters limit the amount of discharge in the system for restoration purposes. The resistive losses in SPS are nearly negligible because of the tightly coupled distribution network.

The system characteristic of electrically integrated SPS is very similar to island microgrid except the fact that it is not automated. It will have a relatively weak power balance since the generator capacity is closely sized to the load demand [16]. In order to maintain shipboard power system reliability, it has to be automated. It is also proved that automation gives better results than manual control. In this process, multiple power generation capabilities abode throughout the ship.

\section{B. DC Shipboard Power System}

The first DC shipboard was in the 1880 s but due to lack of power electronic devices, this system failed [11]. With recent advancements in power electronics devices and storage technologies, the DC SPSs have gained attention. The main motivations for the development of DC SPS are fuel economy and other advantages include:

- Implementation of parallel connection or disconnection for DC power sources will be simple.

- Dispensation from reactive power flow.

- Eliminating harmonic and imbalance problems.

- Unlike variable frequency drives, AC SPS in DC SPS regenerative energy may be easily absorbed in other loads across the DC bus.

- Due to the absence of a power factor in DC distribution, resistive loss in cables is reduced.

There is no need for phase and voltage synchronization in DC SPS. As a result, the generators are quickly brought online and connected to the DC system.

The fuel efficiency of the system operation can be improved by using DC networks by achieving the integration of advanced high speed and high-efficiency diesel generation. Hence, DC Shipboard Power Systems (DCSPSs) keep gaining an increase in research interests. The concept of Onboard DC Grid has two configurations. The first is a multi-drive approach and the second one is a fully distributed system [12]. Another new approach includes components like AC generators, inverter modules, AC motors, etc., but AC switchboard is excluded [13]. Fuelsaving is nearly $20 \%$ with the integration of variable speed diesel generator operating at the optimal speed [14-15].

\section{Proposed DC Shipboard PoWer System MANAGEMENT}

\section{A.System Fault Monitoring}

During steady-state operation systems, fault monitoring and protection are within the limits of healthy operations. Whenever there is any disturbance or sudden change in load, then power varies. The fluctuation in voltage/current has to be detected and cleared immediately in order to maintain reliability. In this paper, the modeled power system includes measuring devices to maintain and continuously monitor the voltage and current parameters. The measuring devices are installed at the terminals of generator, loads and in DC bus. Current, voltage and power thresholds (e.g., a certain percentage of steady-state values) are set in each of the measuring devices to detect a disturbance at a specific location and give signals.

\section{B. Coordinated Control}

In this paper, for DC SPS for power generation, the diesel generators are used. DC SPS follows the HVDC working principle, where the generated AC is converted into DC through converters (i.e., Rectifiers) and given to the load. The load combination is taken with resistance and inductance for nonlinearity. The basic block diagram of the DC shipboard power system is shown in Fig. 1. 




Figure 1. Basic block diagram of DC SPS

The DC bus power is again converted into AC near loads via the inverter. The battery is used as backup i.e., as Energy Storage Device. Power is supplied by three generators with diesel generators prime movers. The basic principle behind the DC ship power system and configuration is like the extension of multiple DC-links. But for these drives, electrical power consumption is more than $80 \%$. In this regard, all DC-links are united in a common DC bus. This approach includes components like AC generators, inverter modules, AC motors, etc., but the AC switchboard is excluded. In AC SPS to control the speed of the motor, a frequency converter consisting of a rectifier and an inverter is used. The AC voltage is first converted to $\mathrm{DC}$ in the rectifier and then inverted back to $\mathrm{AC}$. DC/DC converters are lighter than power transformers, but have a greater efficiency $(>98 \%)$, require less maintenance and their price range is much lower. There are several ways of configuring a DC ship power network. The generators are connected on MV1 Switchboards and the energy is transformed via transformers to the converters. In the multi-drive configuration, all converters are placed in the main switchboard. That simply means that the power cables from generators to the DC bus carry AC current.

\section{Simulation Results ANd Discussions}

\section{A. DC Shipboard Power System Without Solar Panel}

The proposed method is implemented and modeled in MATLAB version 2016a with Intel Quad-core $7^{\text {th }}$ generation as shown in Fig. 2. Two-level Pulse Width Modulated (PWM) voltage source converters are used to convert the AC $(3 \phi, 440 \mathrm{~V}, 60 \mathrm{~Hz})$ power produced by the three-phase generators which are again stepped down using transformers. The DC bus reference voltage is set to $750 \mathrm{~V}$. As the feedback path, Energy Storage System is used with the battery of $650 \mathrm{~V}, 400 \mathrm{Ah}$ and connected to the DC bus through a bi-directional DC/DC converter. In MATLAB for $\mathrm{DC} / \mathrm{DC}$ converter, the half-bridge converter is used. Pulse width modulation has been supplied to it.

Two disturbances are created which occur commonly in the system to validate the feasibility of the proposed approach. Two disturbances are generator loss and load start. The three generator's output power and battery power waveforms are shown in Fig. 3.
Whenever there is a fault in the generation the protecting device, i.e., a circuit breaker isolates the faulted part with the non-faulted path. At generator 3 a fault is generated at $4 \mathrm{sec}$ gets isolated and doesn't generate power. In MATLAB, to produce fault the circuit breaker is set to trip at $4 \mathrm{sec}$.
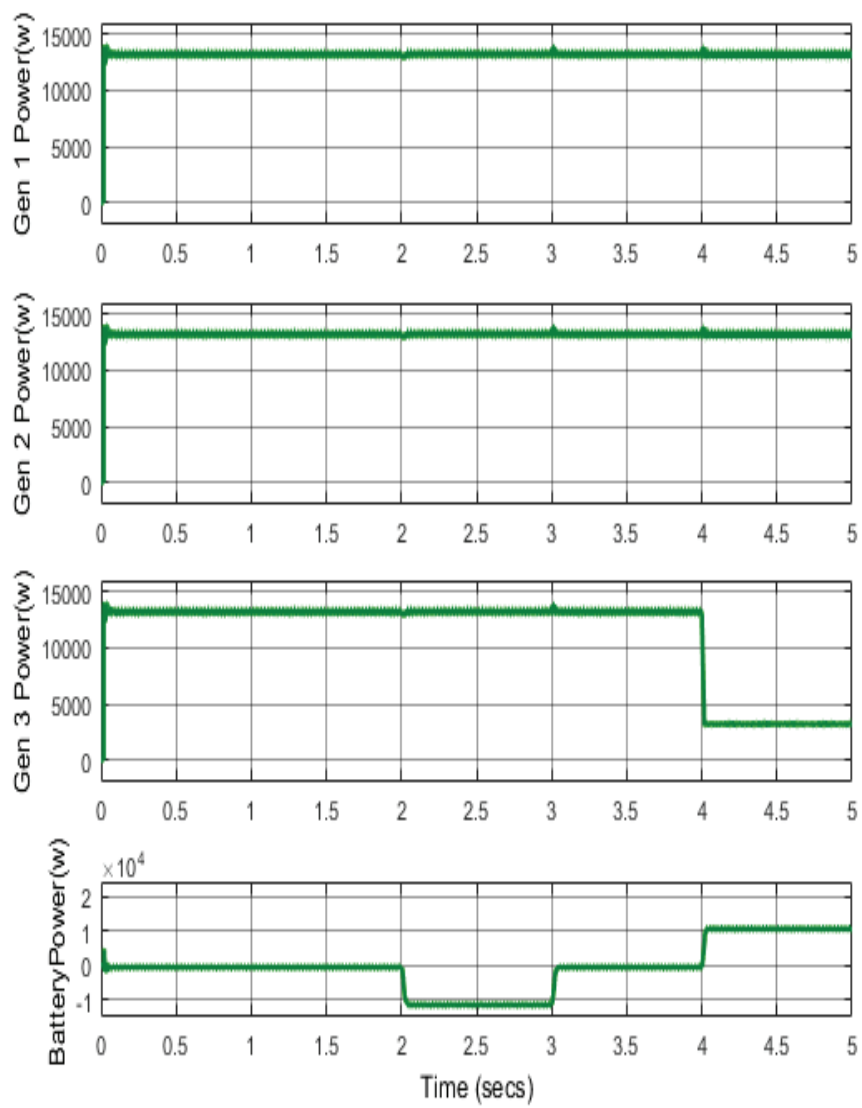

Figure 3. Three generators output power along with the battery power output

Whenever the disturbances occurred in generators and if power generation is lost, the battery supplies the power to the load. In Fig. 3 it is observed that the third generator power is lost for 4 seconds due to generation fault, i.e., power doesn't get supplied to the load. But in this concept, all the bus bars are tied together, and a reference value is set at $750 \mathrm{~V}$ and ESS is set as feedback. Subsequently, whenever there is any fault occurred in power generation, the load gets supplies through the feedback path. Whenever there is a need for power, then the battery in the ESS injects the voltage into the system through a converter. However, the battery injects the power into the system, then the converter acts as a boost converter. 


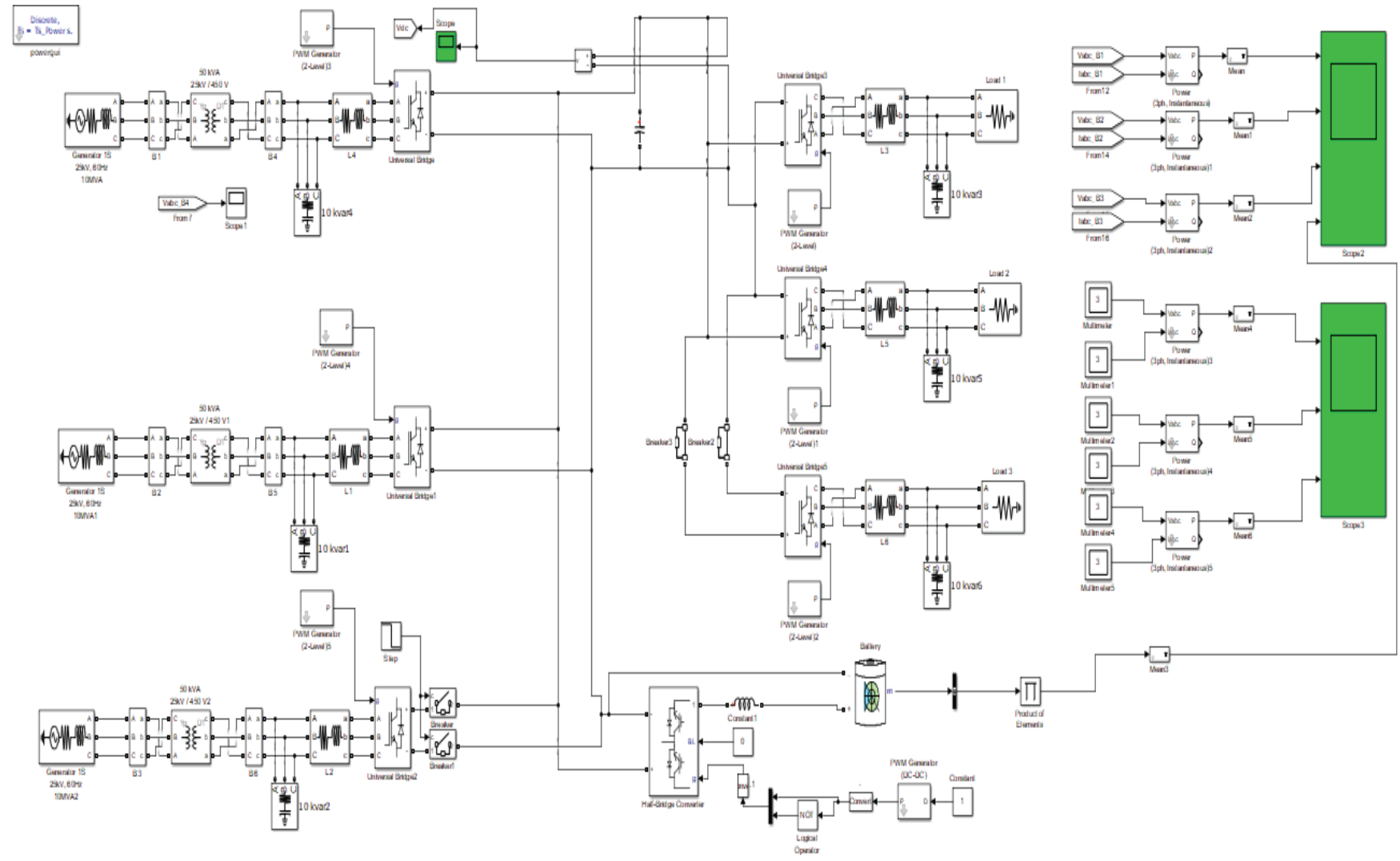

Figure 2. DC shipboard power system model


Figure 4. The output power of three connected load

In Fig.4 it is realized that the load is disconnected at 2-3 seconds, thus during that period, the excess generated power is wasted. Without ESS this power gets wasted. i.e., whenever there are disturbances at load, then the circuit breaker isolates the faulted path with the non-faulted path. At this instant, the power generated is not supplied to load. In order not to waste the excess power the feedback path absorbs the excess power. When extra power is generated, then the ESS device's battery absorbs it through DC/DC converter which acts as a buck converter and absorbs the power. The battery waveform is observed in Fig. 7 that whenever it is observing the excess power generated the battery power. The battery uses extra power to charge itself. The battery is charged whenever there is excess power. The power is balanced by injecting and absorbing. The DC voltage waveform from the $750 \mathrm{~V}$ capacitor is observed in Fig. 5.

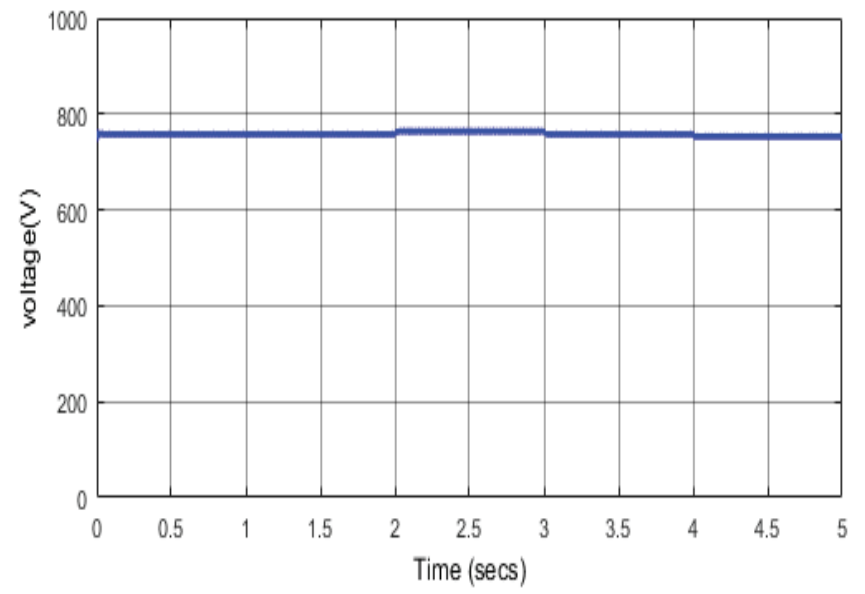

Figure 5. DC voltage from capacitor

Though there are some overshoots when disturbances occurred, it is comprehended that the DC bus voltage kept 
regulated at all points of the disturbance. The power electronics converters quickly recover the voltage regulation as depicted.

\section{B. Shipboard Power System With Solar Panels}

Solar panels are used for power generation in place of generators. The method of using solar panels is modeled and implemented in Matlab is shown in Fig. 6.

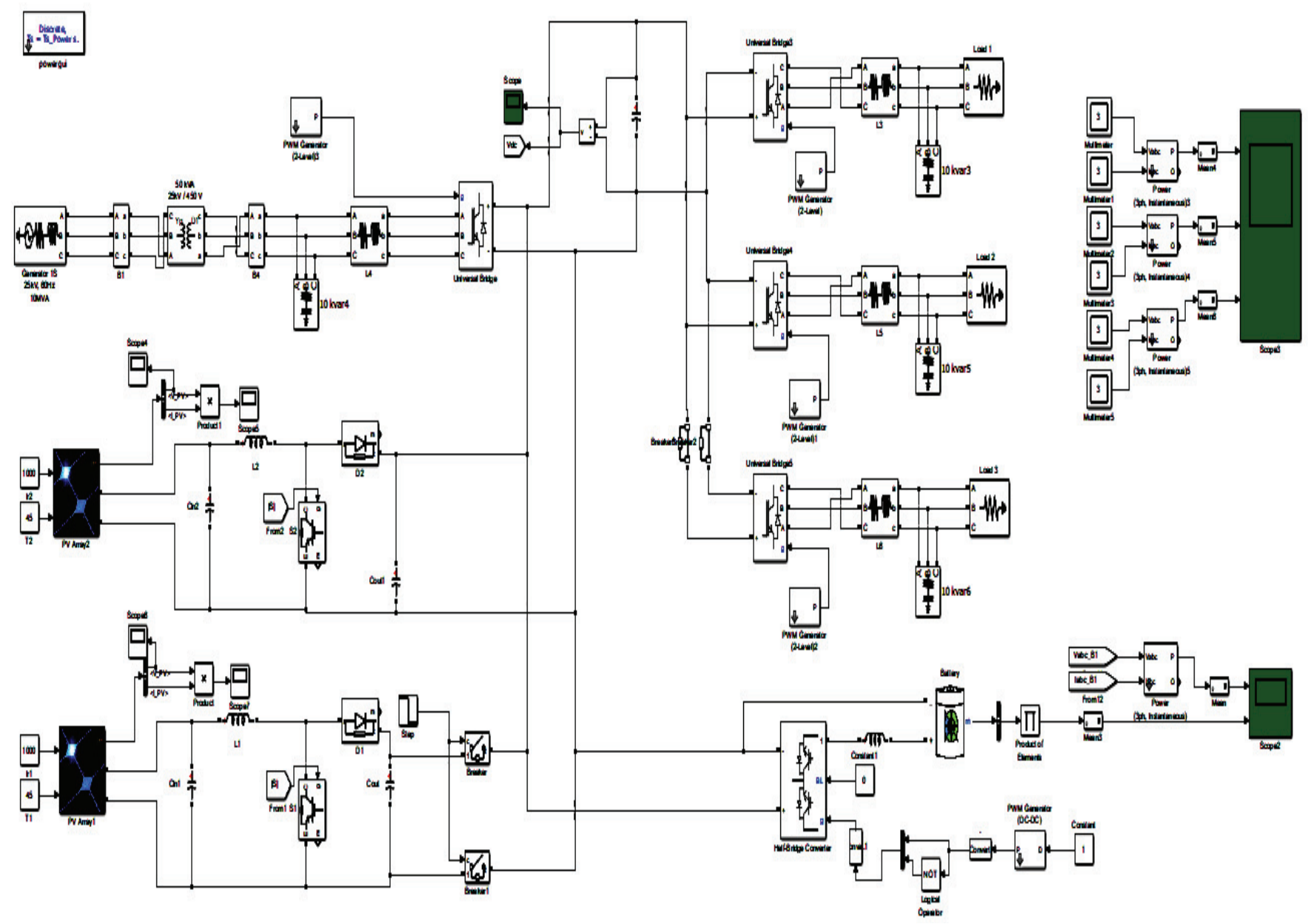

Figure 6. DC SPS using the solar panel

By using solar panels, the battery and electric motors get charged and then the usage of fossil fuels can be reduced. Solar panels directly convert sunlight to electricity. These panels produce reliable electricity without using fossil fuels. The generator 1 output power and battery waveforms are shown in Fig. 7. Only one three-phase generator and two solar panels are used which generates $9 \mathrm{~kW}$ each. The generator 1 produces nearly $13 \mathrm{~kW}$ of power. The battery is used as backup and support and the same relates to a DC/DC converter.


Figure 7. Generator 1 and battery waveform 
The solar panel output power is simulated in Fig. 8. The ship needs approximately $10 \mathrm{~kW}$ of power for a load. Each panel produces $8 \mathrm{~kW}$ of output power.

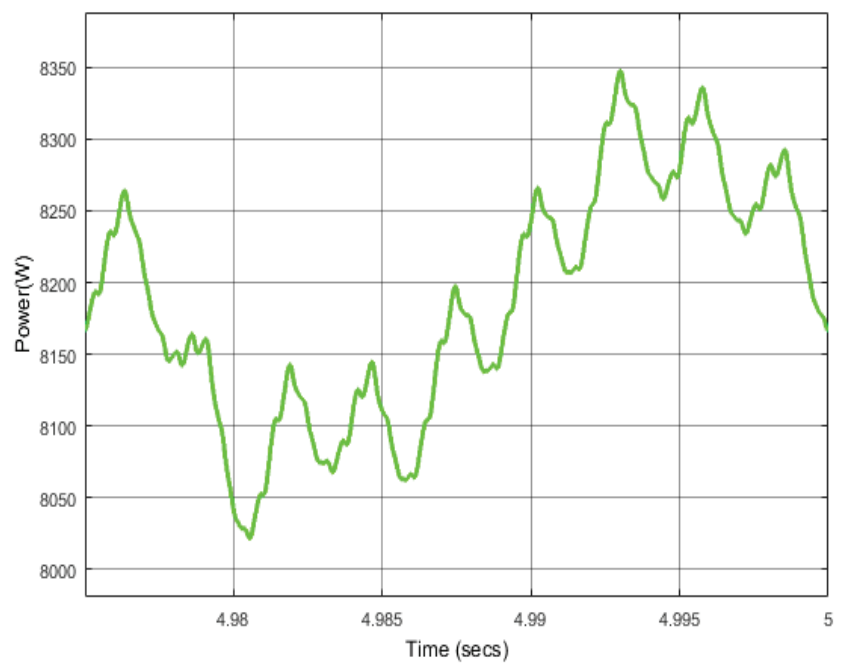

Figure 8. Solar panel output power waveform

The output power of loads is nearly $10 \mathrm{~kW}$ each. The three-load output power is observed in Fig. 9. Whenever there is any interruption in power supply the battery provides power to the loads. If there is any fault at load and if it is isolated, then the generated power is absorbed by the battery.
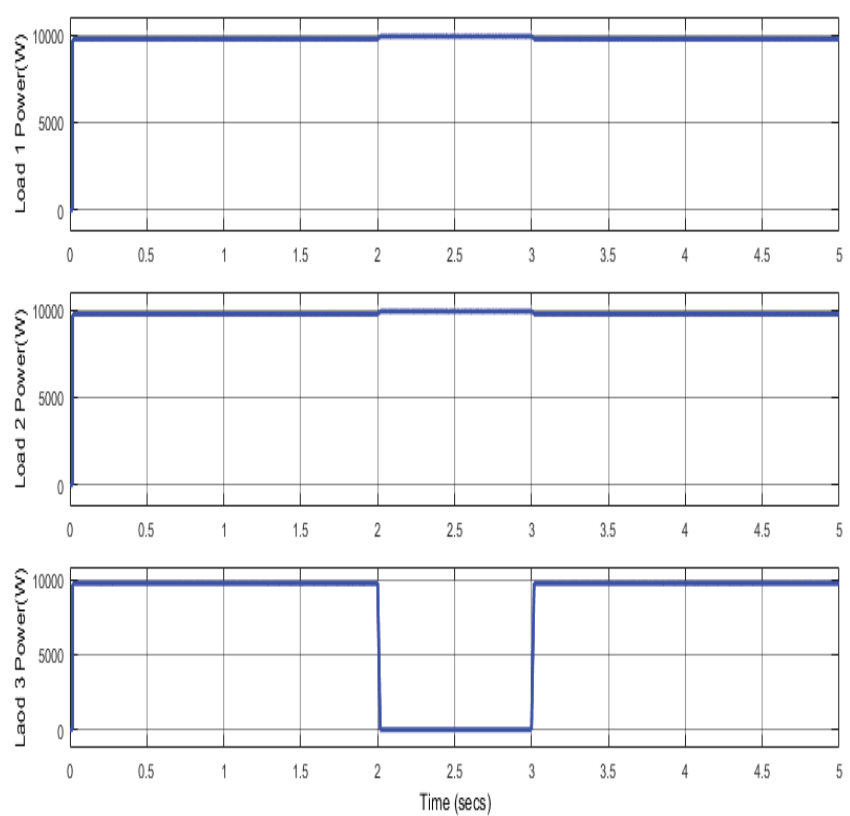

Figure 9. Load output power waveform

The usage of solar panels in this system is because of their benefits. Solar panels are very reliable and require less maintenance. These are static devices so there are no rotational losses. The solar panel system produces power in all types of weather conditions. They produce nearly $80 \%$ of their potential energy on partly cloudy days. Even in the worst cases like extremely cloudy days, they produce $25 \%$ of their total potential.

\section{Conclusions}

This paper proposes the controlling of DC power in the shipboard power system. The proposed method is applied to DC shipboard using solar panels and outcomes are presented. The usage of solar power reduces fuel cost and power generation losses. Moreover, solar power is ecofriendly and a cheaper energy resource. The proposed Energy storage system can produce quality results in terms of controlling DC power in the shipboard. The results indicate that the system remains stable at every instance of time of disturbances, which are introduced at specific intervals of time. Furthermore, the disturbances and faults at generators for the Indian DC shipboard can be investigated.

\section{REFERENCES}

[1] R. G. Blakey, "Power electronics in warships," Power Engineering Journal, vol. 7, no. 2, pp. 65-70, 1993.

[2] Webstar, "Naval experience of power electronics maintenance," IEE Colloquium on Power Electronics Reliability, no. 202, 1998.

[3] Z. Jin, G. Sulligoi, R. Cuzner, L. Meng, J. C. Vasquez, and J. M. Guerrero, "Next-generation shipboard DC power system: introduction smart grid and dc microgrid technologies into maritime electrical networks," IEEE Electrif. Mag., vol. 4, no. 2, pp. 45-57, 2016.

[4] N.Doerry, H.Robey, J.Amy and C.Petry, Powering the future with the integrated power system. Naval Engineers Journal, 108(3), pp.267-282, 1996.

[5] R.Vijay, "Transmission Line Outage Detection and Identification by Communal Spider Optimization Algorithm", CVR Journal of Science and Technology, vol.14, pp.38-42, 2018.

[6] R.Vijay, "Quorum sensing driven bacterial swarm optimization to solve practical dynamic power ecological emission economic dispatch," International Journal of Computational Methods, vol. 15, no. 03, pp.1850089-24, 2018.

[7] G. Seenumani, J. Sun, and H. Peng, "Real-time power management of integrated power systems in all electric ships leveraging multi time scale property," IEEE Transactions on Control Systems Technology, vol. 20, no. 1, pp. 232-240, 2012.

[8] S. Kim, S. Choe, S. Ko, and S. Sul, "A naval integrated power system with a battery energy storage system: Fuel efficiency, reliability, and quality of power," IEEE Electrification Magazine, vol. 3, no. 2, pp. 22-33, 2015.

[9] C.R. Petry and J.W. Rumburg, "Zonal electrical distribution systems: An affordable architecture for the future," Naval Engineers Journal, vol.105, no. 3, pp.45-51, 1993.

[10] F. Shariatzadeh, N. Kumar, and A. K. Srivastava, "Optimal control algorithms for reconfiguration of shipboard microgrid distribution system using intelligent techniques," IEEE Transactions on Industry Applications, vol. 53, no. 1, pp. 474-482, 2017.

[11] Skjong, E. Rodskar, M. Molinas, T. Johansen, and J. Cunningham, "The marine vessel's electrical power system: From its birth to present day," Proceedings of the IEEE, vol. 103, pp. 2410-2424, 2015. 
[12] J. F. Hansen, J. O. Lindtjorn, U.U. Odegaard, T.A. Myklebust, "Increased operational performance of OSVs by Onboard DC Grid," 4th International Conference on Technology and Operation of Offshore Support Vessels, Singapore, 2011.

[13] ABB, "Onboard DC Grid. The step forward in Power Generation and Propulsion," Tech. rep., 2015.

[14] ABB, "The step forward onboard dc grid," Tech. rep., 2014.

[15] W. Koczara and G. Iwanski, "Power Electronics for Renewable and Distributed Energy Systems Variable-Speed Power Generation" Springer, 2013.

[16] K. Hutton, B. Babaiahgari, and J.-D. Park, "A comparative study on electrical distribution systems for the US coast guard's 270-ft medium endurance cutter," North American Power Symposium (NAPS), IEEE, pp. 1-6, 2016. 